\title{
BMJ Open Women's satisfaction with their urban health extension programme and associated factors in Gondar administrative city, northwest Ethiopia: a community-based cross-sectional study
}

\author{
Sisay Molla, ${ }^{1}$ Amsalu Feleke, ${ }^{2}$ Chalie Tadie Tsehay ()$^{2}$
}

To cite: Molla S, Feleke A, Tsehay CT. Women's satisfaction with their urban health extension programme and associated factors in Gondar administrative city, northwest Ethiopia: a community-based cross-sectional study. BMJ Open 2020;10:e039390. doi:10.1136/ bmjopen-2020-039390

- Prepublication history for this paper is available online. To view these files, please visit the journal online (http://dx.doi org/10.1136/bmjopen-2020 039390).

Received 14 April 2020 Revised 21 November 2020 Accepted 24 November 2020

Check for updates

(C) Author(s) (or their employer(s)) 2020. Re-use permitted under CC BY-NC. No commercial re-use. See rights and permissions. Published by BMJ.

'University of Gondar Students' Clinic, University of Gondar, Gondar, Ethiopia

${ }^{2}$ Health Systems and Policy, University of Gondar, Gondar, Ethiopia

Correspondence to Chalie Tadie Tsehay; chatadie78@gmail.com

\section{ABSTRACT}

Objectives Ethiopia is a developing country striving to achieve universal health coverage using the health extension programme. There is limited evidence about Ethiopian women's satisfaction with their urban health extension programme. Thus, this study was aimed at assessing the level of women's satisfaction with their urban health extension services and associated factors in Gondar administrative city of northwest Ethiopia and elucidate factors associated with its access and use.

Design Cross-sectional study.

Setting Community.

Participants Randomly selected 744 women were interviewed using a structured interviewer-administered questionnaire.

Outcome Satisfaction of women over 17 years of age with their urban health extension programme (use and services).

Results Some $29.4 \%$ (95\% Cl 26.2 to 32.5 ) of women were satisfied with their urban health extension programme. Divorced women (adjusted OR (AOR): $0.35,95 \% \mathrm{Cl} 0.14$ to 0.85 ), women in the age group of $45-53$ years (AOR: 0.35 , $95 \% \mathrm{Cl} 0.14$ to 0.85 ), private employees (AOR: $0.35,95 \% \mathrm{Cl}$ 0.14 to 0.85 ), unsatisfactory knowledge (AOR: $0.13,95 \% \mathrm{Cl}$ 0.07 to 0.25 ) and perceived accessibility of health extension workers (AOR: $0.99,95 \% \mathrm{Cl} 0.06$ to 0.17 ) were factors associated with women's satisfaction with their urban health extension programme.

Conclusions Women's satisfaction with their urban health extension programme was low. This finding was associated with age, marital status, occupation, knowledge of participants and women's perceived accessibility of services. Therefore, increasing awareness about the programme, promoting and improving accessibility of services, particularly by mothers, may augment the utilisation of the programme ultimately leads to efficient use of scarce healthcare resources in Ethiopia.

\section{INTRODUCTION}

Universal health coverage has been considered as a strategy to improve the well-being of the community particularly in the framework of resources-limited countries. ${ }^{12}$ Developing countries are struggling to achieve universal
Strengths and limitations of this study

- Knowing women's satisfaction with urban Health Extension Programme (HEP) could maximise healthcare utilisation and cost effectiveness; essential knowledge for healthcare planners.

- The sample size met stringent criteria for generalisation to HEP in comparable urban areas.

- Socially desirable responses were minimised with separate and private interview areas.

- Participants recalled their last 12 months' exposure to the urban HEP; thus, recall bias may be a factor.

health coverage after the Alma-Ata declaration of 'Health for all by the year 2000' movement. ${ }^{3}$ Despite the efforts applied, nearly $99 \%$ of the global maternal and child deaths occurred in developing countries in the year 2015, two-thirds contributed by sub-Saharan Africa. ${ }^{45}$ A study done among 137 counties showed that 15.6 million extra deaths were recorded in low-income and middle-income countries in 2016 alone. Nearly one-fourth of these deaths were directly attributed to the non-utilisation of health services. ${ }^{2}$ Besides, nearly one-third of the world populations do not use healthcare services. ${ }^{6}$

Indeed, the health service utilisation rate in Africa is low, especially in sub-Saharan Africa which ranges from 0.2 to 2 visits per annum, particularly in Ethiopia it's suggested to be about 0.25 visits per person per year, which is very far from the 3 visits of WHO and Millennium Development Goals. The poor utilisation could presumably put the people to different preventable disease crises which are reflected by a higher degree of maternal and child mortality and consequently affect the country's and individual's economy. ${ }^{7}$ According to the 2016 Ethiopian Demographic and Health Survey report, about $88 \%$ 
of urban residents had been drinking untreated water, $16 \%$ of urban households used improved toilet facilities, high teenage childbearing (13\%), contraceptive utilisation was only $36 \%$, low institutional delivery $(26 \%)$ and low postnatal care $(17 \%){ }^{8}$

The low utilisation of the programme is directly affected by service users' satisfaction as it is one of the determinants of customer devotion to service utilisation. ${ }^{9-11}$ Prior studies also confirmed that satisfaction positively affects customer loyalty. ${ }^{12-14}$

Sociodemographic characteristics, waiting time, women's knowledge and attitude about the programme, women's perception of technical competency of professionals, perceived accessibility of services, and perception of interpersonal relationships are some of the factors affecting women's satisfaction with the services provided. ${ }^{915-17}$

Recognising the aforementioned health problems, Ethiopia had introduced an innovative Health Extension Programme (HEP) at rural and urban levels which aims at improving the health status of the community through the provision of primary healthcare services. ${ }^{18}$ The urban HEP has been implemented since 2009 at the national level to ensure equity and equal access to essential health services for urban communities focusing on promotive, preventive and selected curative health services. The programme services have been accessed to the community through information transformation at the household level and maternal and child health services at health posts. ${ }^{618-21}$

Current Ethiopia's healthcare delivery is structured into primary, secondary, and tertiary levels of care. The HEP is placed and managed under the control of the primary healthcare unit. ${ }^{22}$

Furthermore, the programme encompasses about 15 packages which are provided free of charge to everyone regardless of any conditions. These packages are thematised into four major categories; hygiene and environmental sanitation (solid and liquid waste disposal, personal hygiene and healthy home environment, food and water safety and latrine construction and utilisation), family health (maternal and child health, nutrition, family planning, youth, and adolescent health and immunisation), disease prevention and control (malaria, tuberculosis and leprosy, HIV/AIDS, non-communicable diseases and mental illness) and prevention and control of injury (first aid and referral services). ${ }^{16102324}$

The packages are primarily implemented by female nurses called urban health extension workers (HEWs) who have special training on the packages. ${ }^{25}$ Urban HEWs are expected to spend $75 \%$ of their working hours on home to a home visit or outreach activities to improve the health status of the community. ${ }^{6} 1023$ They also provide facilitybased basic services such as immunisation and injectable contraceptives and selected curative services such as first aid and case referrals to the health centres. ${ }^{22}{ }^{24}{ }^{26}$ Besides, urban HEWs are responsible for graduating model families by providing training for households and health developmental armies in the community. ${ }^{27}$ Households who completed $75 \%$ of the training hours and implemented more than $85 \%$ of the packages will be graduated as model households. ${ }^{28}$ Health developmental armies are selected from model households and they are responsible to supervise 30 households to connect them in one to five networks. These strategies are found to be basics to detect the bottlenecks of low service utilisation and efficient use of resources at the community level in Ethiopia. ${ }^{27}$

Other high-income, middle-income as well as lowincome countries that are stressed with chronic conditions and focused on more expensive primary care can get lessons and improve their community health by scaling up initiatives from Ethiopia, such as defining community priorities through community engagement and empowerment of household members and promoting their ability to solve local problems. HEP also stresses the institutionalisation of efforts that resolve the viability of community services through a high degree of political engagement and successful alignment of national policies and leverage. ${ }^{29}$ On top of the above essential and cost-effective packages implementation and structures, multiple site-specific studies would have a paramount effect on the achievement of the national programme. ${ }^{12}$ A community-based study conducted in the Hadiya zone revealed that the majority $(67.4 \%)$ of respondents were satisfied with the services provided by urban (HEWs). ${ }^{10}$ Whereas a study in Gamo Gofa zone, southern Ethiopia showed that $37.4 \%$ of participants were satisfied with the health extension service. ${ }^{30}$

However, the magnitude of women's satisfaction and the associated factors on the programme has been unstudied in Gondar administrative city. Therefore, this study aimed to examine the magnitude of women's satisfaction with their urban HEP and associated factors in Gondar administrative city. The findings of this study will elucidate components of services that promote greater satisfaction, hence helps to improve the quality of service delivery.

\section{METHODS}

\section{Study design and setting}

A community-based cross-sectional study was conducted from 1 March to 30 April 2019, in Gondar administrative city, which is one of the three metropolitan cities in the Amhara National Regional State. The city is located 176 and $755 \mathrm{~km}$ far from Bahir-Dar, the capital of the Amhara region, and Addis Ababa, the capital of Ethiopia, respectively. Administratively, the city is divided into 12 subcities with 90847 households and a total of 390644 people, of these 194541 were females. There was a total of 76 urban health extension professionals assigned in all subcities.

Women in Gondar administrative city were the source population, whereas women in the selected subcities were the study population. Women aged 18 years and older, who had been living in the selected household for more 
than 6 months and who used urban HEP services for the last year were included in the study.

\section{Sample size determination and sampling procedures}

The sample size was determined using the single population proportion formula $\left(\mathrm{Z}_{\alpha / 2}\right)^{2} * \mathrm{P}(1 \mathrm{P}) /(\mathrm{d})^{2}$ assuming a $67.4 \%$ proportion $(\mathrm{P})$ of women's satisfaction,,${ }^{10} 95 \% \mathrm{CI}$, $5 \%$ marginal error (d), design effect of $2 \%$ and $10 \%$ nonresponse rate that gave a sample of 744 women.

A multistage sampling technique was applied. Initially, four subcities $(30 \%)$ of the total subcities were selected using the lottery method. Then, the sample was proportionally allocated to each subcity. Finally, a computergenerated simple random sampling technique was used to select the study participants. For a household having more than one eligible individual, only one respondent was selected and interviewed.

\section{Variables and measurements}

The dependent variable of the study was women's satisfaction. It was measured using 16 items of satisfaction measurement questions with a 5-point Likert scale ( $1=$ strongly disagree, $2=$ disagree, $3=$ neutral, $4=$ agree and $5=$ strongly agree). The sum of these items gave a total score of minimum 16 and a maximum 80 with a mean score of 45.9 and also the Cronbach's alpha score was 0.935 . Accordingly, when the women scored $>45.9$ (the mean value), we considered them as 'satisfied', otherwise as 'unsatisfied'. ${ }^{10}$

The independent variables were sociodemographic characteristics (such as age, marital status, educational status, monthly income, religion, and occupation), knowledge and attitude of respondents about HEP, perception of participants about HEWs (competency, interpersonal relationship, and ways of communication, time spent and access to HEWs).

Knowledge was measured using seven items of questions and participants who scored greater than or equal to four out of the seven questions, we considered as having 'satisfactory knowledge', otherwise as 'unsatisfactory knowledge'. The Cronbach's alpha value for the seven items of questions was 0.942 .

The attitude was measured using six items of questions with a 5-point Likert scale (1=strongly disagree to $5=$ strongly agree). Participants who scored greater than or equal to the mean score (22.2) were categorised as having a 'favourable attitude' and below the mean score considered as 'unfavourable attitude' and the Cronbach's alpha score was $0.673 .^{10}$

\section{Data collection tools and procedures}

An interviewer-administered standardised structured questionnaire was developed after reviewing relevant studies. ${ }^{10}$ The questionnaire was first prepared in English and translated into the local language (Amharic) and finally back to English to ensure consistency. Four trained diploma nurses and two BSc degree graduates were recruited as data collectors and supervisors, respectively.
One day training was given to data collectors and supervisors on the objectives of the study, data collection tools, procedures and handling of participants' concerns without introducing biases.

Data were collected through the home-to-home visit with separate and secured areas to maintain the respondents' privacy. For those participants who were on job or out of their home during the data collection period, the data were collected during the weekend and after working hours.

\section{Data processing and analysis}

The collected data were entered and cleaned using Epi info V.7 and exported to SPSS V.20 for analysis. Both descriptive statistics and binary logistic regression analyses were done. Variables with $p$ values of less than 0.2 in the bivariable logistic regression analysis were candidates for the multivariable logistic regression analysis. In the final multivariable logistic regression analysis, a $\mathrm{p}$ value of less than 0.05 and adjusted OR (AOR) with 95\% CI were used to identify statistically associated factors with women's satisfaction.

\section{Patient and public involvement}

No patient or the public were directly involved in the development of the research questions, the design, results and dissemination plan of the study. However, the participants and administrative officials were informed about the research questions, objectives and data collection process. The findings were disseminated to the Gondar administrative city health department. On top of that, the results will be distributed to potential stakeholders who are involved in the programme implementation after publishing on a peer-reviewed scientific reputable journal. Informed written consent was obtained from each participant after a brief explanation of the research objectives and data collection process of the study. Participants were also informed about their right to withdraw at any time or to skip for a single question or number of questions. After ensuring their volunteerism, those participants who could read and write signed on the space provided. Whereas, for those who were unable to read and write, a fingermark (finger thumb) was taken. Finally, the confidentiality of the information was maintained by omitting personal identifiers.

\section{RESULTS}

\section{Sociodemographic characteristics of participants}

A total of 744 women responded to the intervieweradministered questionnaire. About $43 \%$ were between the age of 27 and 35 years and $61.8 \%$ were married. Religious preference for $66.8 \%$ of the women was Orthodox Christian; $53.1 \%$ attended college or above, while $5.5 \%$ went to primary school; and $22.8 \%$ were government employees (table 1).

\section{Knowledge and attitude towards the urban HEP}

The mean score of study participants' knowledge about urban HEP was 4 and more than half $(52.6 \%)$ of the 
Table 1 Sociodemographic characteristics of participants in Gondar administrative city, northwest Ethiopia, 2019 $(\mathrm{n}=744)$

\begin{tabular}{|c|c|c|}
\hline Variables & $\begin{array}{l}\text { Frequency } \\
\text { (n) }\end{array}$ & $\begin{array}{l}\text { Percentage } \\
(\%)\end{array}$ \\
\hline \multicolumn{3}{|l|}{ Age in years } \\
\hline 18-26 & 57 & 7.7 \\
\hline $27-35$ & 320 & 43 \\
\hline $36-44$ & 239 & 32.1 \\
\hline $45-53$ & 83 & 11.1 \\
\hline 53 & 45 & 6 \\
\hline \multicolumn{3}{|l|}{ Marital status } \\
\hline Married & 460 & 61.8 \\
\hline Single & 159 & 21.4 \\
\hline Divorced & 66 & 8.9 \\
\hline Windowed & 59 & 7.9 \\
\hline \multicolumn{3}{|l|}{ Educational status } \\
\hline Unable to read and write & 139 & 18.7 \\
\hline Read and write & 59 & 7.9 \\
\hline Primary school (grades 1-8) & 41 & 5.5 \\
\hline $\begin{array}{l}\text { Secondary school (grades } \\
9-12)\end{array}$ & 110 & 14.8 \\
\hline College or above & 395 & 53.1 \\
\hline \multicolumn{3}{|l|}{ Occupation } \\
\hline Government employee & 170 & 22.8 \\
\hline Private employee & 159 & 21.4 \\
\hline Housewives & 261 & 35.1 \\
\hline Merchant & 94 & 12.6 \\
\hline Daily labourer & 60 & 8.1 \\
\hline \multicolumn{3}{|l|}{ Religion } \\
\hline Orthodox Christian & 497 & 66.8 \\
\hline Muslim & 222 & 28.8 \\
\hline Protestant & 25 & 3.4 \\
\hline
\end{tabular}

participants had satisfactory knowledge. Similarly, the mean score of the study participants' attitude towards urban HEP was 22.2. A large fraction $(87.4 \%)$ of participants had a favourable attitude towards the urban HEP.

\section{Perceived interpersonal relationship, competency and accessibility}

Slightly more than half $(52.3 \%)$ of the respondents perceived that HEWs had a positive interpersonal relationship with women. Most of the respondents $(84.8 \%)$ knew that urban HEWs in-person. Moreover, $44.5 \%$ of the study participants perceived that urban HEWs had good communication. Two hundred sixty-eight women responded that urban HEWs were accessible (table 2).

\section{Overall women's satisfaction}

The overall women's satisfaction with their urban HEP was found to be $29.4 \%$ (95\% CI 26.2 to 33.2 ; table 3 ).
Table 2 Women's perception of urban health extension workers (HEWs) interaction in Gondar administrative city, northwest Ethiopia, $2019(n=744)$

\begin{tabular}{|c|c|c|}
\hline Variables & Responses & Frequency (\%) \\
\hline \multirow{2}{*}{$\begin{array}{l}\text { Perceived technical } \\
\text { competency }\end{array}$} & Competent & $335(45.0)$ \\
\hline & Not competent & $409(55.0)$ \\
\hline \multirow{2}{*}{$\begin{array}{l}\text { Perceived interpersonal } \\
\text { relationship }\end{array}$} & Good interaction & 389 (52.3) \\
\hline & Poor interaction & $355(47.7)$ \\
\hline \multirow[t]{2}{*}{ Perceived time spent } & Good time spent & $413(44.5)$ \\
\hline & Less time spent & 331 (55.3) \\
\hline \multirow[t]{2}{*}{$\begin{array}{l}\text { Perceived way of } \\
\text { communication }\end{array}$} & $\begin{array}{l}\text { Good } \\
\text { communication }\end{array}$ & 331 (44.5) \\
\hline & $\begin{array}{l}\text { Poor } \\
\text { communication }\end{array}$ & $413(55.5)$ \\
\hline \multirow{2}{*}{$\begin{array}{l}\text { Perceived accessibility } \\
\text { of HEWs }\end{array}$} & Accessible & 268 (36.0) \\
\hline & Not accessible & 476 (64.) \\
\hline
\end{tabular}

Factors associated with women's satisfaction with their urban HEP

In the multivariable logistic regression analysis, age, marital status, educational status, occupation, perceived accessibility of urban HEWs and knowledge of women on urban HEP were significantly associated with women's satisfaction with their urban HEP.

Accordingly, divorced women were $65 \%$ less likely to be satisfied by their urban HEP than married participants (AOR: $0.35,95 \%$ CI 0.14 to 0.85 ). Women in the age group of 45-53 years were 3.9 times more likely to be satisfied than those age group of 18-26 years (AOR: $3.9,95 \%$ CI 1.12 to 13.8 ). Privately employed women were $63 \%$ less likely to be satisfied compared with governmental employees (AOR: 0.37, 95\% CI 0.19 to 0.75 ). Women who had unsatisfactory knowledge about urban HEP were $87 \%$ less likely to be satisfied than those who had satisfactory knowledge (AOR: $0.13,95 \%$ CI 0.07 to $0.25)$. Moreover, those who had a good perception of the accessibility of HEWs were $1 \%$ less likely to be satisfied compared with their counterparts (AOR: 0.99, 95\% CI 0.06 to 0.17 ; table 4 ).

\section{DISCUSSION}

Overall, in the study field, $29.4 \%$ of women were satisfied with their urban HEP in the study area. The finding of this study showed that more than two-thirds of women were not happy with the services provided by the programme, which would have a negative influence on their service utilisation. This result was higher than that of a study done in Shanghai, China $(25.4 \%) \cdot{ }^{31}$ In shanghai, the provision of essential drugs was included in the study which significantly reduced their satisfaction. On the other hand, our study was focused on service packages that do not include essential drugs. However, the finding was lower than studies conducted in the Gamo Gofa zone, Ethiopia $(37.4 \%),{ }^{30}$ Hadiya zone, Ethiopia 
Table 3 Overall women's satisfaction with their urban health extension programme (HEP) in Gondar Administrative city, northwest Ethiopia, $2019(n=744)$

\begin{tabular}{|c|c|c|c|c|c|}
\hline & $\begin{array}{l}\text { Strongly } \\
\text { disagree }\end{array}$ & Disagree & Undecided & Agree & $\begin{array}{l}\text { Strongly } \\
\text { agree }\end{array}$ \\
\hline Variables & $\mathbf{N}(\%)$ & $\mathbf{N}(\%)$ & $\mathbf{N}(\%)$ & $\mathbf{N}(\%)$ & $\mathbf{N}(\%)$ \\
\hline HEWs services provision was comfortable & $203(27.3)$ & $388(52.2)$ & $11(1.5)$ & $134(18.0)$ & $8(1.1)$ \\
\hline Urban HEP saved time & $207(27.8)$ & $369(49.8)$ & $22(3.0)$ & $138(18.5)$ & $8(1.1)$ \\
\hline Urban HEP saved money & $214(28.8)$ & $373(50.1)$ & $16(2.2)$ & $126(16.9)$ & $15(2.0)$ \\
\hline Urban HEWs gave quality services & $33(4.4)$ & $226(30.4)$ & $314(42.2)$ & $155(20.8)$ & $16(2.2)$ \\
\hline Urban HEWs did not use medical terms for communication & $218(29.3)$ & $314(42.2)$ & $15(2.0)$ & $160(21.5)$ & $37(5.0)$ \\
\hline Convenience of office hours to visit HEWs & $204(27.4)$ & $355(47.7)$ & $16(2.2)$ & $151(20.3)$ & $18(2.4)$ \\
\hline Wanted to visit HEWs in the future & $70(9.4)$ & $154(20.7)$ & $375(50.4)$ & $131(17.6)$ & $14(1.9)$ \\
\hline Urban HEWs treated in a friendly manner & $208(28.0)$ & $374(46.6)$ & $10(1.3)$ & $160(21.5)$ & $19(2.6)$ \\
\hline Urban HEWs' explanation was easy to understand & $208(28.0)$ & $294(39.5)$ & $25(3.4)$ & $203(27.5)$ & $14(1.9)$ \\
\hline Urban HEWs encouraged to talk for all concerns & $186(25.0)$ & $342(46.0)$ & $13(1.7)$ & $182(24.5)$ & $21(2.8)$ \\
\hline Provide information to others to use urban HEP & $27(3.6)$ & $167(22.4)$ & $360(48.4)$ & $175(23.5)$ & $15(2.0)$ \\
\hline Urban HEWs used quality instruments for medical care & $177(23.8)$ & $295(39.7)$ & $120(16.1)$ & $129(17.3)$ & $23(3.1)$ \\
\hline Cleanness of the health post was good & $87(11.7)$ & $232(31.2)$ & $29(3.9)$ & $267(35.9)$ & $129(17.3)$ \\
\hline Urban HEWs were courteous and respectful & $26(3.5)$ & $127(17.1)$ & $10(1.3)$ & $382(51.3)$ & $199(26.7)$ \\
\hline Urban HEWs spent more time during home to home visit & $181(24.3)$ & $415(55.8)$ & $10(1.3)$ & $118(15.9)$ & $20(2.7)$ \\
\hline Urban HEWs teach about mental health continuously & $215(30.2)$ & $460(61.8)$ & $5(0.7)$ & $46(6.2)$ & $8(1.1)$ \\
\hline
\end{tabular}

HEWs, health extension workers.

$(67.4 \%),{ }^{10}$ and Jimma zone $(69.6 \%) .{ }^{23}$ The community members of Gamo Gofa were voluntarily participating in the planning process of the programme that implied community involvement during problem identification, in planning and service evaluation could improve not only their understanding but also their responsibility sharing of the programme services. Unlike Jimma's study, this study was conducted among urban-dwelling women. Poor community acceptance of the HEP, which implies in some areas, the community still gives more attention to curative healthcare services. ${ }^{23} 3233$ Moreover, the presence of limited supportive supervision, as well as lack of in-service training, which is a bottleneck to implement the HEP, would contribute to the discrepancy among the two studies. ${ }^{22} 2332$ The result is further complemented by a study in Ethiopia in which limited supportive supervision was one of the challenges to implement HEP. ${ }^{22}$

Divorced women were $65 \%$ less likely to be satisfied with their urban HEP than that of married women, which is in agreement with studies done in the Jimma Zone, ${ }^{34}$ Turkey $^{35}$ and the Republic of Serbia. ${ }^{36}$ The tendency of increasing healthcare demand including (but are not limited to) family planning, institutional delivery, antenatal care and immunisation services among married individuals is higher than divorced. Besides, there may be high spousal support that enhances healthcare adherence among married women. ${ }^{34} 3738$

The findings of this study showed that privately employed women were $63 \%$ less likely to be satisfied with their urban HEP compared with governmental employees. This might be due to the inconvenient time to meet HEWs during their home visits among privately employed women. The other justification could be some of the private employees earn a higher amount of money so that they might have advanced healthcare demand compared with governmental employees. However, this discrepancy could be solved by enhancing the engagement of private sectors.

Those participants in the age category of $45-53$ years were 3.9 times more likely to be satisfied with their urban HEP than those who were in the age group of 18-26 years, which is in agreement with studies done in Abuna Gindeberet District, Ethiopia, ${ }^{39}$ Boston, America ${ }^{40}$ and the Republic of Serbia. ${ }^{36}$ This group of community is disproportionately susceptible to develop chronic diseases as a result, they would seek to get healthcare from the programme which ultimately boosts their satisfaction. ${ }^{341}$

Participants who had unsatisfactory knowledge were $87 \%$ less likely to be satisfied than their counterparts. This result was in line with the study findings in Abuna Gindeberet district, Oromia Regional State, Ethiopia and another study in Ethiopia. ${ }^{139}$ The possible reason might be the fact that as knowledge increases the likelihood of services utilisation increases and subsequently satisfaction could be enhanced. ${ }^{1}$

This study revealed that $52.6 \%$ of women had satisfactory knowledge. This was lower than the study findings conducted in Akaki Addis Ababa $(60 \%)^{42}$ and Abuna Gindeberet Shewa zone $(58.4 \%)^{43}$ and higher than the study finding in Debre Tabor $(38.9 \%) \cdot{ }^{44}$ It could be the 
Table 4 Multivariable logistic regression analysis of factors associated with women's satisfaction with their urban health extension programme (HEP) in Gondar administrative city, northwest Ethiopia, 2019 ( $n=744)$

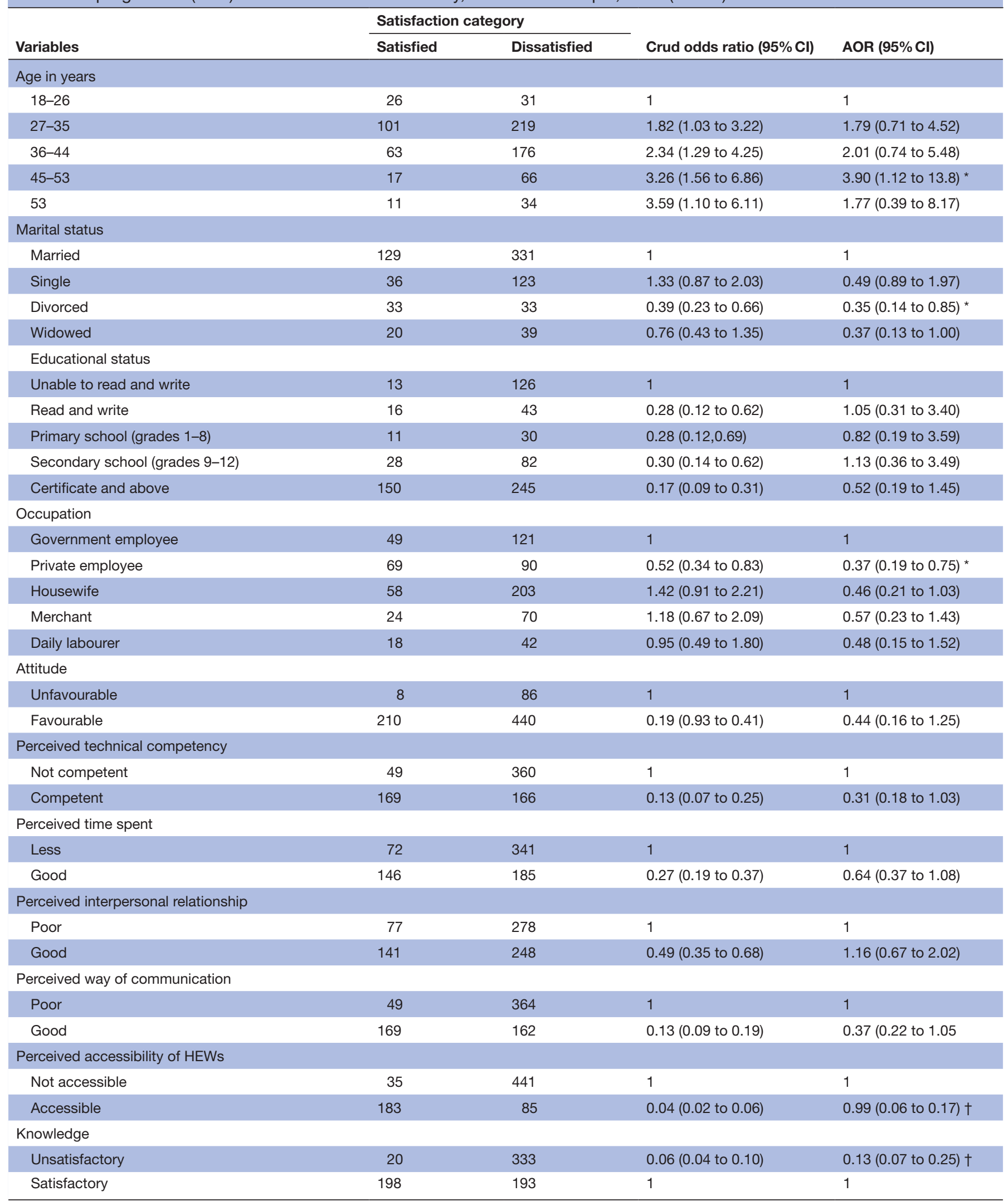

*Statically significant at $p<0.05$.

†Statically significant at a $p<0.001$.

AOR, adjusted OR; HEWs, health extension workers. 
difference in measurement, in the current study, knowledge was assessed based on fifteen programme packages whereas in the above studies it was assessed using only solid and liquid west management packages, which is one of the four programme thematic areas. ${ }^{10}$

Furthermore, participants who had good access to urban HEP were $1 \%$ less likely to be satisfied with their urban HEP than those who had poor access. The study in Hadiya zone supported the result of this study (25.2\%) less satisfied. ${ }^{10}$ The descriptive result $(34.6 \%)$ was less than that of a study conducted in the Jimma zone $(51 \%) .{ }^{23}$ But this finding is contradicted with a study done on model households in Ethiopia and showed that women who were visited frequently by HEWs were 1.3 times more likely to visit health posts than women who did not get frequent visits. ${ }^{45}$ This could be due to the participants' level of exposure to the programme. Model households are more engaged and graduated to HEP compared with none model households that enhance their satisfaction. This discrepancy might be also explained by the high expectation but low availability of services such as drugs, equipment, long waiting times and poor interpersonal relationships $(50.3 \%)$ in this study. The other reason might be the inadequate number of staff, unfavourable working environment, lack of commitment to serve the community and lack of intense supervision.

\section{Limitation of the study}

Even though the women were interviewed with separate and privacy secured areas, using a structured intervieweradministered questionnaire, still social desirability bias could be a factor. Similarly, the women were interviewed about the last 12 months of exposure; there might also be recall bias.

\section{CONCLUSIONS}

The present study clearly showed that the majority of respondents were not satisfied with the services provided by the urban HEP. Age, marital status, occupation, knowledge of participants towards HEP as well as the accessibility of HEWs were factors associated with women's satisfaction towards their urban HEP. Therefore, awareness creation about urban HEP, improving the accessibility of services, promotion of services and improving the frequency of home visits will increase women's satisfaction with their urban HEP in Ethiopia.

Acknowledgements The authors would like to thank all respondents for their willingness to participate in the study and gave valuable information. They are also thankful to the Gondar administrative city health office for providing a supportive letter and the University of Gondar, Institute of Public Health staff, for their technical supports. Finally, their appreciation should go to data collectors and supervisors for their unreserved contribution to the data collection process.

Contributors SM carried out the study, participated in tool development, coordinated the data collection activity and participated in the statistical analysis. AF participated in the design of the study, developed the tool, CTT, performed the statistical analysis, participated in tool development, participated in the design of the study, and drafting the manuscript. All authors read and approved the final manuscript.
Funding The authors have not declared a specific grant for this research from any funding agency in the public, commercial or not-for-profit sectors.

Competing interests None declared.

Patient consent for publication Not required.

Ethics approval Ethical clearance was obtained from the University of Gondar Institute of Public Health Research Ethics Review Board (Ref. No. IPH/180/06/210). A supporting letter was obtained from Gondar Administrative City Health Office (Ref. No.GCA/04) and confidentiality of the information was maintained by omitting personal identifiers.

Provenance and peer review Not commissioned; externally peer reviewed.

Data availability statement All data relevant to the study are included in the article or uploaded as supplementary information.

Open access This is an open access article distributed in accordance with the Creative Commons Attribution Non Commercial (CC BY-NC 4.0) license, which permits others to distribute, remix, adapt, build upon this work non-commercially, and license their derivative works on different terms, provided the original work is properly cited, appropriate credit is given, any changes made indicated, and the use is non-commercial. See: http://creativecommons.org/licenses/by-nc/4.0/.

ORCID iD

Chalie Tadie Tsehay http://orcid.org/0000-0001-5264-3858

\section{REFERENCES}

1 Tafesse N, Gesessew A, Kidane E. Urban health extension program model housing and household visits improved the utilization of health services in urban Ethiopia: a community-based cross-sectional study. BMC Health Serv Res 2019;19:31.

2 Kruk ME, Gage AD, Joseph NT, et al. Mortality due to lowquality health systems in the universal health coverage era: a systematic analysis of amenable deaths in 137 countries. Lancet 2018;392:2203-12.

3 Mekonnen Girmay A R, Evans M, Gari S, et al. Urban health extension service utilisation and associated factors in the community of Gullele sub-city administration, Addis Ababa. Ethiopia 2019.

4 Singh R, Neogi SB, Hazra A, et al. Utilization of maternal health services and its determinants: a cross-sectional study among women in rural Uttar Pradesh, India. J Health Popul Nutr 2019;38:13.

5 Okedo-Alex IN, Akamike IC, Ezeanosike OB, et al. Determinants of antenatal care utilisation in sub-Saharan Africa: a systematic review. BMJ Open 2019;9:e031890.

6 Black RE, Taylor CE, Arole S, et al. Comprehensive review of the evidence regarding the effectiveness of community-based primary health care in improving maternal, neonatal and child health: 8. summary and recommendations of the expert panel. $J$ Glob Health 2017;7:010908.

7 Bazie GW, Adimassie MT. Modern health services utilization and associated factors in North East Ethiopia. PLoS One 2017;12:0185381.

8 Federal democratic republic of Ethiopia. Demographic and health survey central statistics agency, 2016.

9 Akowuah JA, Agyei-Baffour P, Awunyo-Vitor D. Determinants of antenatal healthcare utilisation by pregnant women in third trimester in Peri-Urban Ghana. J Trop Med 2018;2018:1673517-8.

10 Sibamo EL, Berheto TM. Community satisfaction with the urban health extension service in South Ethiopia and associated factors. BMC Health Serv Res 2015;15:160.

11 Khan AA, Siddiqui AZ, Mohsin SF, et al. Sociodemographic characteristics as predictors of satisfaction in public and private dental clinics. Pak J Med Sci 2018;34:1152-7.

12 Ware JE, Snyder MK, Wright WR, et al. Defining and measuring patient satisfaction with medical care. Eval Program Plann 1983;6:247-63.

13 de Ruyter K, Wetzels M. Customer equity considerations in service recovery: a cross-industry perspective. International Journal of Service Industry Management 2000;11:91-108.

14 Manzoor F, Wei L, Hussain A, et al. Patient Satisfaction with Health Care Services; An Application of Physician's Behavior as a Moderator. Int J Environ Res Public Health 2019;16:3318.

15 Merga H, Fufa T. Impacts of working environment and benefits packages on the health professionals' job satisfaction in selected public health facilities in eastern Ethiopia: using principal component analysis. BMC Health Serv Res 2019;19:494.

16 Steenland M, Dula J, de Albuquerque A, et al. Effects of appointment scheduling on waiting time and utilisation of antenatal care in Mozambique. BMJ Glob Health 2019;4:e001788. 
17 Lee Y, Kasper JD. Assessment of medical care by elderly people: general satisfaction and physician quality. Health Serv Res 1998;32:741-58.

18 Admassie A, Abebaw D, Woldemichael AD. Impact evaluation of the Ethiopian health services extension programme. J Develop Effect 2009;1:430-49.

19 Banteyerga $\mathrm{H}$. Ethiopia's health extension program: improving health through community involvement. MEDICC Rev 2011;13:46-9.

20 Witter S, Anderson I, Annear P, et al. What, why and how do health systems learn from one another? insights from eight lowand middle-income country case studies. Health Res Policy Syst 2019;17:9.

21 Jikamo B, Woelamo T, Samuel M. Utilisation of urban health extension programme services and associated factors among Hosanna dwellers, Hadiya zone southern Ethiopia: a community based cross-sectional study, 2019.

22 Assefa Y, Gelaw YA, Hill PS, et al. Community health extension program of Ethiopia, 2003-2018: successes and challenges toward universal coverage for primary healthcare services. Global Health 2019;15:24.

23 Birhanu Z, Godesso A, Kebede Y, et al. Mothers' experiences and satisfactions with health extension program in Jimma zone, Ethiopia: a cross sectional study. BMC Health Serv Res 2013;13:74.

24 Gizaw AT, Zebre G, Tareke KG. Implementation, experience and challenges of urban health extension programme in Addis ababa: a case study from Ethiopia, 2020.

25 Workie NW, Ramana GN. The health extension programme in Ethiopia, 2013

26 Nuamah GB, Agyei-Baffour P, Mensah KA, et al. Access and utilization of maternal healthcare in a rural district in the forest belt of Ghana. BMC Pregnancy Childbirth 2019;19:6.

27 Annis E, Ratcliffe H. Strengthening primary health care systems to increase effective coverage and improve health outcomes in Ethiopia: PHCPI, 2019. Available: https://improvingphc. org/ strengthening-primary

28 Fetene N, Linnander E, Fekadu B, et al. The Ethiopian health extension program and variation in health systems performance: what matters? PLoS One 2016;11:e0156438.

29 Wang H, Tesfaye R, Ramana GNV, et al. Ethiopia health extension programme: an institutionalised community approach for universal health coverage. World Bank Publications, 2016.

30 Mergia M, Shegaze M, Ayele G, et al. Mothers' satisfaction with health extension services and the associated factors in Gamo Goffa zone, southern Ethiopia. PLoS One 2020;15:e0232908.

31 Li Z, Hou J, Lu L, et al. On residents' satisfaction with community health services after health care system reform in Shanghai, China, 2011. BMC Public Health 2012;12:S9.
32 Ethiopian Public Health Institute. Improving health extension programme in Ethiopia. An evidence-based policy brief, 2014.

33 Ngugi AK, Agoi F, Mahoney MR, et al. Utilization of health services in a resource-limited rural area in Kenya: prevalence and associated household-level factors. PLoS One 2017;12:e0172728.

34 Girma F, Jira C, Girma B. Health services utilization and associated factors in jimma zone, South West Ethiopia. Ethiop $\mathrm{J}$ Health Sci 2011;21:85-94.

35 Baltaci D, Eroz R, Ankaralı H, et al. Association between patients sociodemographic characteristics and their satisfaction with primary health care services in turkey. Kuwait Medical Journal 2013;45:291-9.

36 Djordjevic I, Vasiljevic D. The effect of sociodemographic factors on patient satisfaction with health care system. Serb J Experiment Clin Res 2018;20.

37 Maharjan B, Rishal P, Svanemyr J. Factors influencing the use of reproductive health care services among married adolescent girls in Dang district, Nepal: a qualitative study. BMC Pregnancy Childbirth 2019;19:152.

38 Pandey KR, Yang F, Cagney KA, et al. The impact of marital status on health care utilization among Medicare beneficiaries. Medicine 2019;98:e14871.

39 Kelbessa Z, Baraki N, Egata G. Level of health extension service utilization and associated factors among community in Abuna Gindeberet district, West Shoa zone, Oromia regional state, Ethiopia. BMC Health Serv Res 2014;14:324.

40 Hall JA, Dornan MC. Patient sociodemographic characteristics as predictors of satisfaction with medical care: a meta-analysis. Soc Sci Med 1990;30:811-8.

41 Carrasquillo O. Health care utilisation. In: Gellman MD, Turner JR, eds. Encyclopedia of behavioral medicine. New York: Springer, 2013: 909-10.

42 Bultume MD, Sanders D, HM D. Utilisation of the health extension programme services in Akaki district: Ethiopia, 2011. Available: http://etd.uwc.ac.za/handle/11394/1771

43 Argaw $\mathrm{H}$. The health extension programme (HEP) of Ethiopia: summary of concepts, progress, achievements and challenges. WHO Ethiopia Country Office, 2007.

44 Gadallah M, Zaki B, Rady M, et al. Patient satisfaction with primary health care services in two districts in lower and upper Egypt. East Mediterr Health J 2003;9:422-30.

45 Yitayal M, Berhane Y, Worku A, et al. Health extension program factors, frequency of household visits and being model households, improved utilization of basic health services in Ethiopia. BMC Health Serv Res 2014;14:156. 